\title{
Craniosynostosis, Boston type
}

INSERM

\section{Source}

INSERM. (1999). Orphanet: an online rare disease and orphan drug data base.

Craniosynostosis, Boston type. ORPHA:1541

Craniosynostosis, Boston type is a form of syndromic craniosynostosis, characterized by a highly variable craniosynostosis with frontal bossing, turribrachycephaly and cloverleaf skull anomaly. Hypoplasia of the supraorbital ridges, cleft palate, extra teeth and limb anomalies (triphalangeal thumb, 3-4 syndactyly of the hands, a short first metatarsal, middle phalangeal agenesis in the feet) have also been described. Associated problems include headache, poor vision, and seizures. Intelligence is normal. 